\title{
Design and Control of Ethanol/Benzene Separation by Energy-Saving Extraction-Distillation Process Using Glycerol as an Effective Heavy Solvent
}

\author{
Supporting Information \\ Wei-Cheng Shen and I-Lung Chien* \\ Department of Chemical Engineering \\ National Taiwan University
}

Taipei, 10617 Taiwan

Revised: July 5, 2019

* Corresponding author. I-Lung Chien, Tel: +886-2-3366-3063; Fax: +886-2-2362-3040; E-mail: ilungchien@ntu.edu.tw 
This text file is the supporting information for the paper "Design and Control of Ethanol/Benzene Separation by Energy-Saving Extraction-Distillation Process Using Glycerol as an Effective Heavy Solvent"

Table S1. Ethanol/Benzene azeotropic information at 1 atm (mole basis)

Table S2. Basis of economics and equipment sizing

Figure S1 Thermodynamic validation of ternary liquid-liquid-equilibrium for the ethanol-benzene-glycerol system (a) Aspen built-in model in Table 1a at 298.15 K (b) New model in Table $1 \mathrm{~b}$ at $298.15 \mathrm{~K}$.

Figure S2 Thermodynamic validation of binary vapor-liquid-equilibrium for the ethanol-benzene pair (a) Aspen built-in model in Table 1a at 1 atm (b) New model in Table $1 \mathrm{~b}$ at $1 \mathrm{~atm}$.

Figure S3 Thermodynamic validation of binary vapor-liquid-equilibrium for the glycerol-ethanol pair (a) Aspen built-in model in Table 1a at 1 atm (b) New model in Table $1 \mathrm{~b}$ at $1 \mathrm{~atm}$.

Figure S4 Sequential iterative optimization procedure for (a) Scheme I (b) Scheme II.

Figure S5 Optimization results for Scheme I of important design variables.

Figure S6 Optimization results for Scheme II of important design variables.

Figure S7 Density difference of each stage in the extraction column for Scheme II.

Figure S8 (a) Open-loop sensitivity test with reboiler duty (QR1) on temperature profile in the stripping column (b) Closed-loop sensitivity test on temperature profile in the stripping column. 
Table S1. Ethanol/Benzene azeotropic information at $1 \mathrm{~atm}$ (mole basis)

\begin{tabular}{cccc}
\hline & Literature $^{34}$ & Aspen Built-in & LLE Prediction \\
& & \\
\hline Temp.(K) & 340.95 & 340.90 & 347.08 \\
Ethanol & 0.4403 & 0.4457 & 0.3779 \\
Benzene & 0.5597 & 0.5443 & 0.6221 \\
\hline
\end{tabular}


Distillation column

Column diameter (D): Aspen tray sizing

Column length (L): NT trays with $2 \mathrm{ft}$ spacing plus 20\% extra length

Capital cost $=17,640(\mathrm{D})^{1.066}(\mathrm{~L})^{0.802}(\mathrm{D}$ and $\mathrm{L}$ are in meters)

Condenser (area in $\mathrm{m}^{2}$ )

Heat-transfer coefficient $=0.852 \mathrm{~kW} / \mathrm{K} \cdot \mathrm{m}^{2}$

Differential temperature $=$ condenser temperature $-315 \mathrm{~K}$

Capital cost $=7296(\text { area })^{0.65}$

Reboiler (area in $\mathrm{m}^{2}$ )

Heat-transfer coefficient $=0.568 \mathrm{~kW} / \mathrm{K} \cdot \mathrm{m}^{2}$

Differential temperature $=$ steam temperature - base temperature $(\Delta \mathrm{T}>20 \mathrm{~K})$

Capital cost $=7296(\text { area })^{0.65}$

Cooler (area in $\mathrm{m}^{2}$ )

Heat-transfer coefficient $=0.568 \mathrm{~kW} / \mathrm{K} \cdot \mathrm{m}^{2}$

Differential temperature $=$ LMTD of (inlet and outlet temperature differences)

Capital cost $=7296(\text { area })^{0.65}$

Heat exchangers, liquid-to-liquid (area in $\mathrm{m}^{2}$ )

Heat-transfer coefficient $=0.852 \mathrm{~kW} / \mathrm{K}-\mathrm{m}^{2}$

Differential temperature $=$ LMTD of (inlet and outlet temperature differences)

Capital cost $=7296(\text { area })^{0.65}$

Flash Tank

1. Maximum vapor velocity

F-factor $=V_{\max } \rho_{\mathrm{v}}{ }^{1 / 2}$

In English Engineering Units: F-Factor $=0.5, \mathrm{~V}_{\max }=[\mathrm{ft} / \mathrm{sec}], \rho_{\mathrm{v}}=\left[\mathrm{lb} / \mathrm{ft}^{3}\right]$

2. Liquid holdup

5 min liquid holdup time with liquid half full

An aspect ratio of 2 is used.

Capital cost $=17,640(\mathrm{D})^{1.066}(\mathrm{~L})^{0.802}(\mathrm{D}$ and $\mathrm{L}$ are in meters $)$

Extraction column

Length: NTE trays with $4 \mathrm{ft}$ HETP plus additional $3 \mathrm{ft}$ at the top and $3 \mathrm{ft}$ at the bottom

Diameter: following calculations on page 583 of Seider et al. ${ }^{38}$ with maximum total liquid throughput $=$ $120 \mathrm{ft}^{3} / \mathrm{h} \cdot \mathrm{ft}^{2}$ and safety factor $f=0.6$

Capital cost $=17,640(\mathrm{D})^{1.066}(\mathrm{~L})^{0.802}(\mathrm{D}$ and $\mathrm{L}$ are in meters)

Vacuum system $^{38}$

1. Steam ejector

Size factor (S): flow rate (lb/hr)/suction pressure (torr)

Cost multiplying factor $\left(\mathrm{C}_{\mathrm{M}}\right)$ :

One-stage $=1.0$, two-stages $=1.8$, three-stages $=2.1$

Steam used amount is assumed to be 10 times of flowrate

Operating cost $=($ Steam consumption $) *($ LP steam cost $)$ 
Capital cost $=1690\left(\mathrm{C}_{\mathrm{M}}\right)(\mathrm{S})^{0.41}$

2. Liquid-ring pump

Size factor (S): flow rate $\left(\mathrm{ft}^{3} / \mathrm{min}\right)$

Operating cost $=$ compressor power consumption

Capital cost $8250(\mathrm{~S})^{0.35}$

Energy cost

HP steam = USD 9.88/GJ (41 barg, 527.15 K)

MP steam $=$ USD 8.22/GJ $(10 \mathrm{barg}, 457.15 \mathrm{~K})$

LP steam $=$ USD 7.78/GJ $(5$ barg, $433.15 \mathrm{~K})$

Cooling water $(315 \mathrm{~K})=\mathrm{USD} 0.354 / \mathrm{GJ}$

Chilled water at $278.15 \mathrm{~K}$, return at $288.15 \mathrm{~K}=\mathrm{USD} 4.43 / \mathrm{GJ}$

Electricity $=$ USD $16.9 / \mathrm{GJ}$

$\mathrm{TAC}=($ total capital cost/payback period $)+$ annual energy cost

Payback period $=3$ years; Operating time $=8000$ hours $/$ year 
Figure S1. Thermodynamic validation of ternary liquid-liquid-equilibrium for the ethanol-benzene-glycerol system (a) Aspen built-in model in Table 1a at 298.15 K (b) New model in Table $1 \mathrm{~b}$ at $298.15 \mathrm{~K}$.

(a)

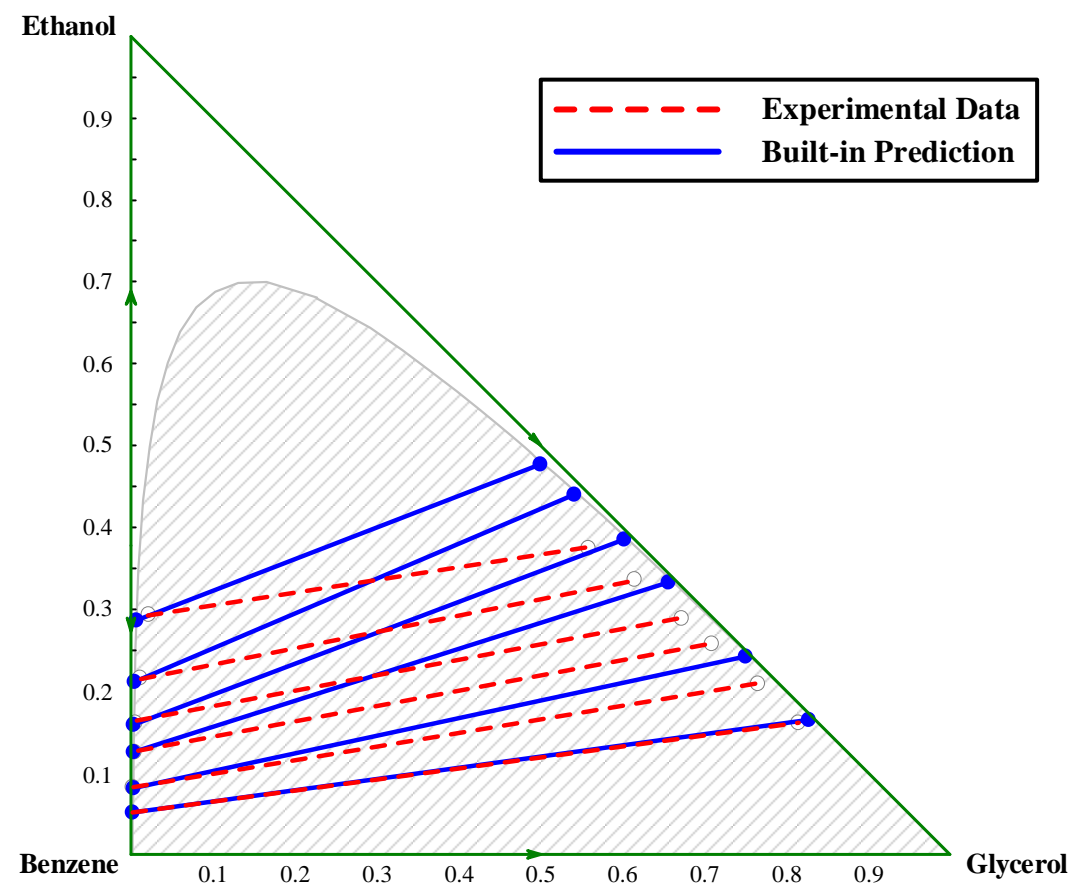

(b)

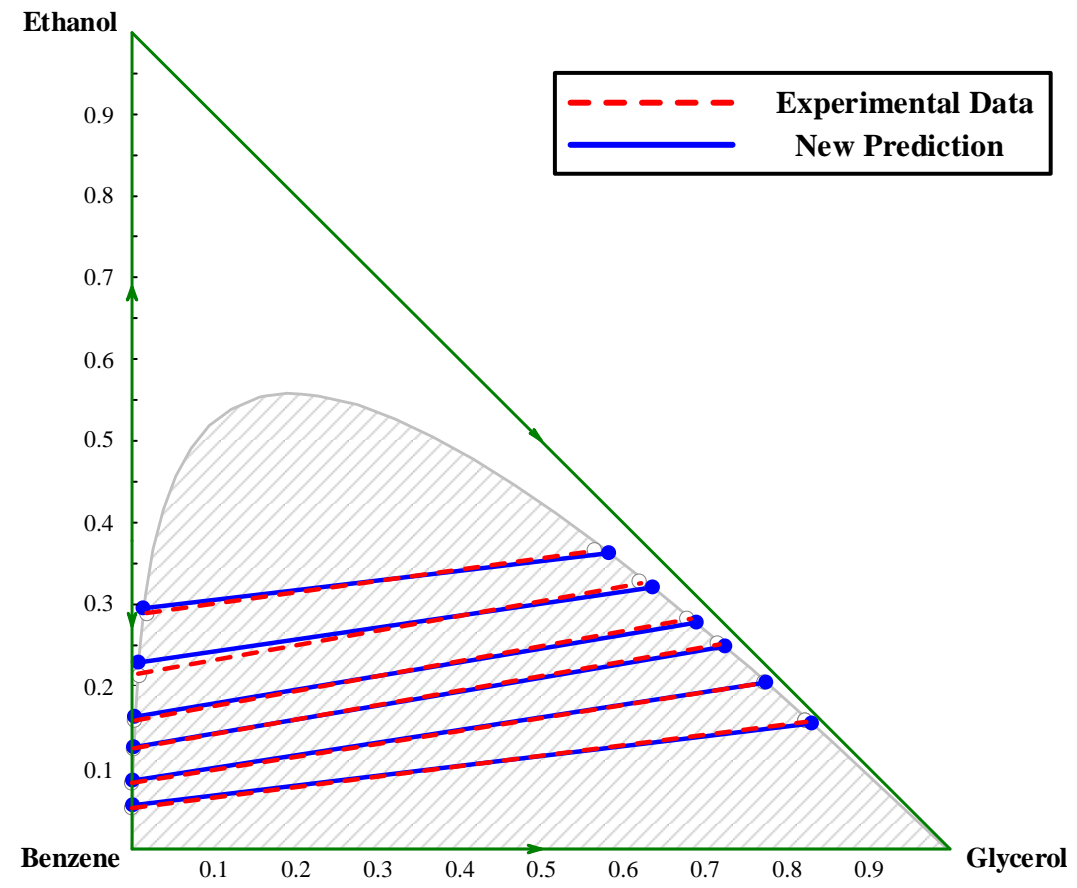


Figure S2. Thermodynamic validation of binary vapor-liquid-equilibrium for the ethanol-benzene pair (a) Aspen built-in model in Table 1a at 1 atm (b) New model in Table $1 \mathrm{~b}$ at $1 \mathrm{~atm}$.

(a)

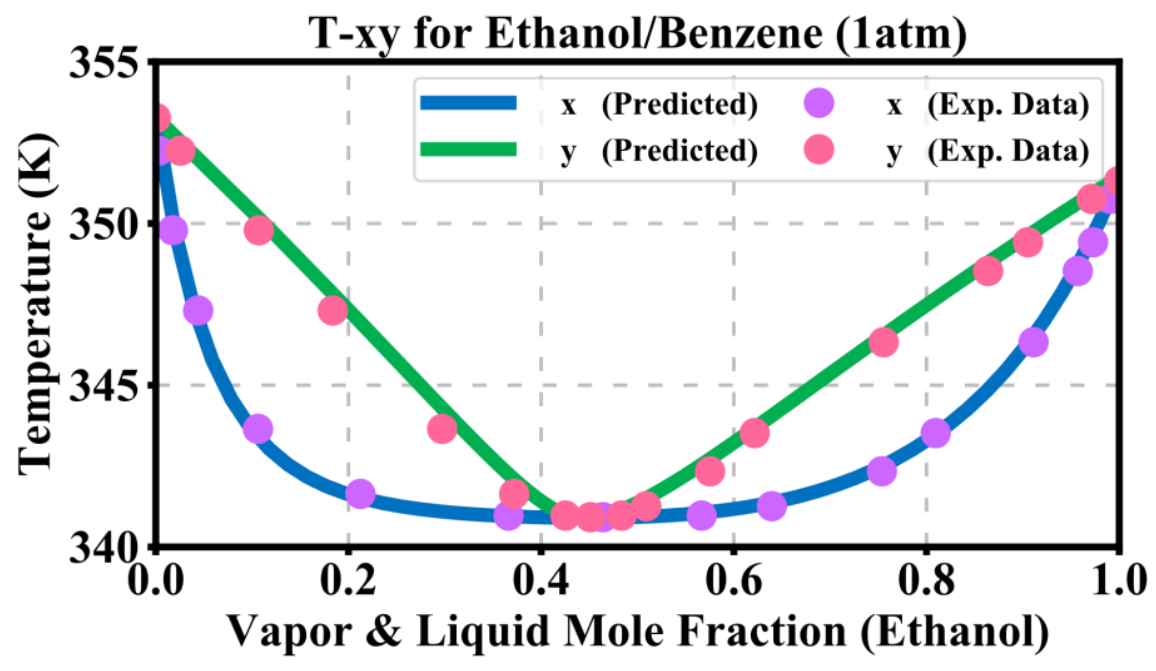

(b)

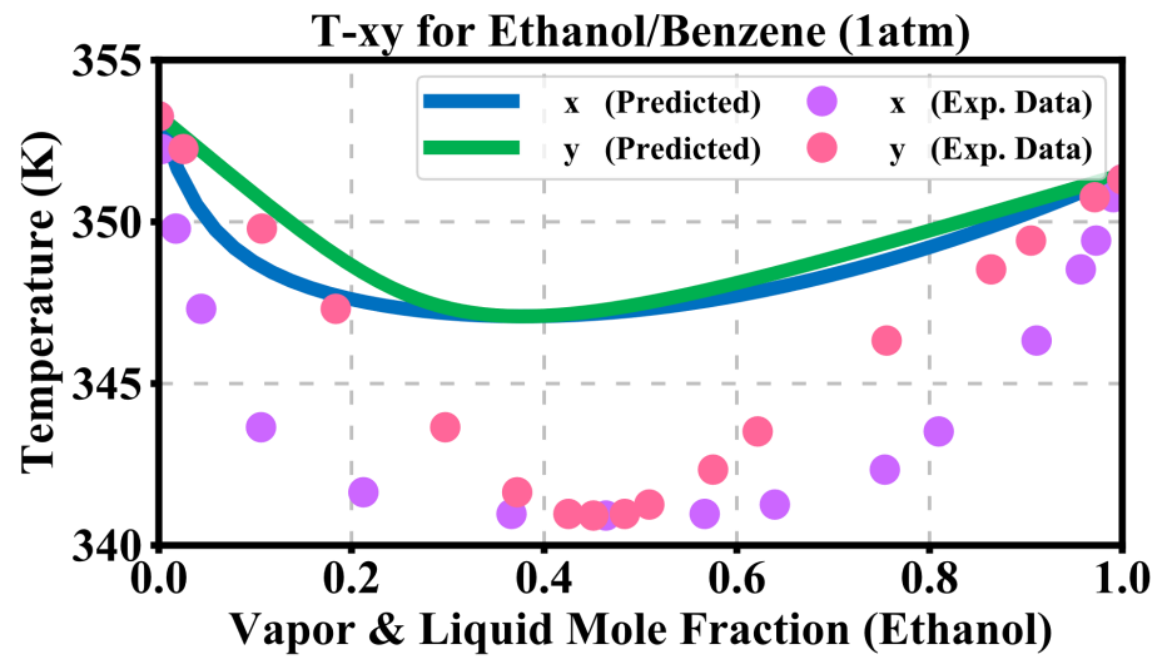


Figure S3. Thermodynamic validation of binary vapor-liquid-equilibrium for the glycerol-ethanol pair (a) Aspen built-in model in Table 1a at 1 atm (b) New model in Table $1 \mathrm{~b}$ at $1 \mathrm{~atm}$.

(a)

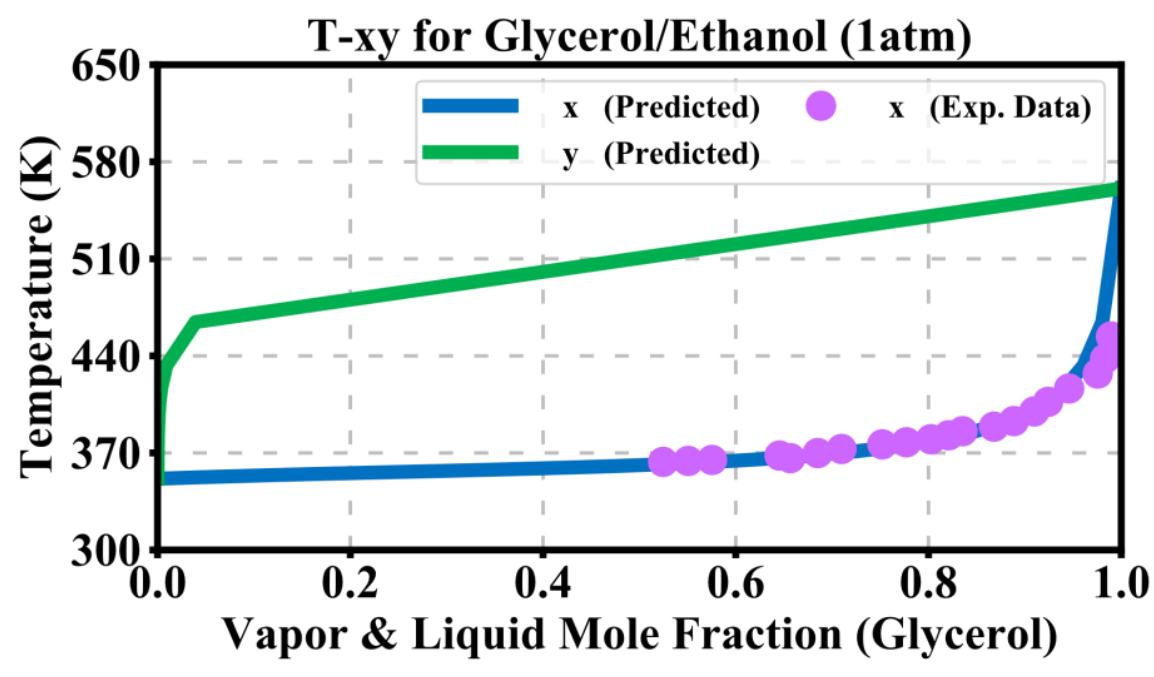

(b)

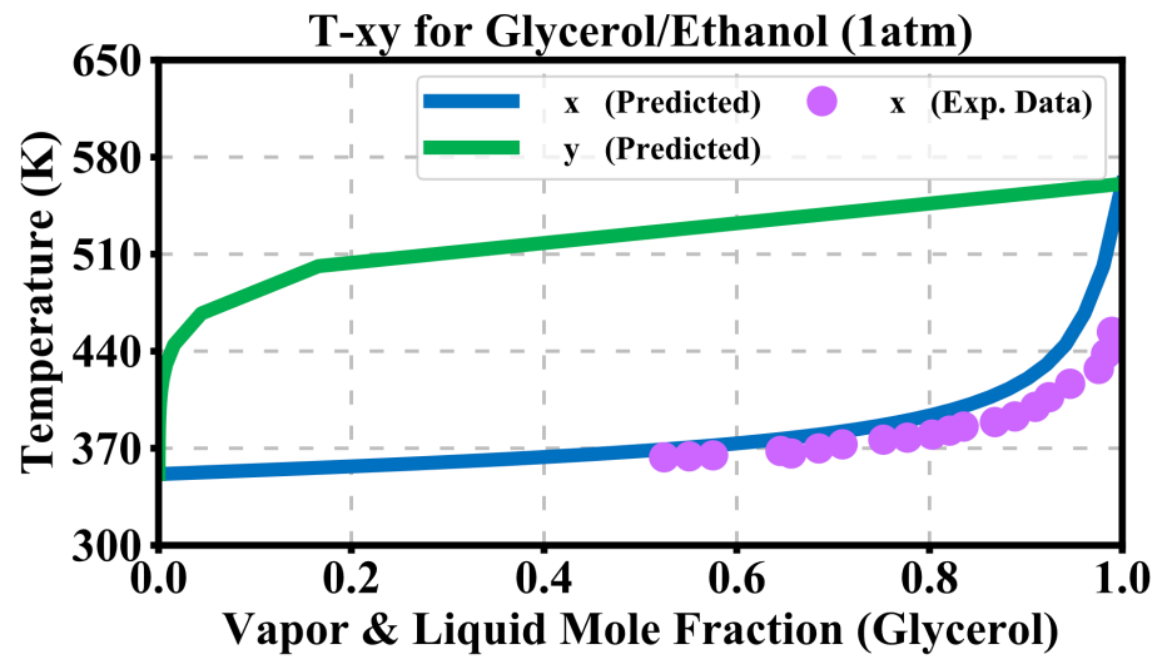


Figure S4. Sequential iterative optimization procedure for (a) Scheme I (b) Scheme II.

(a)

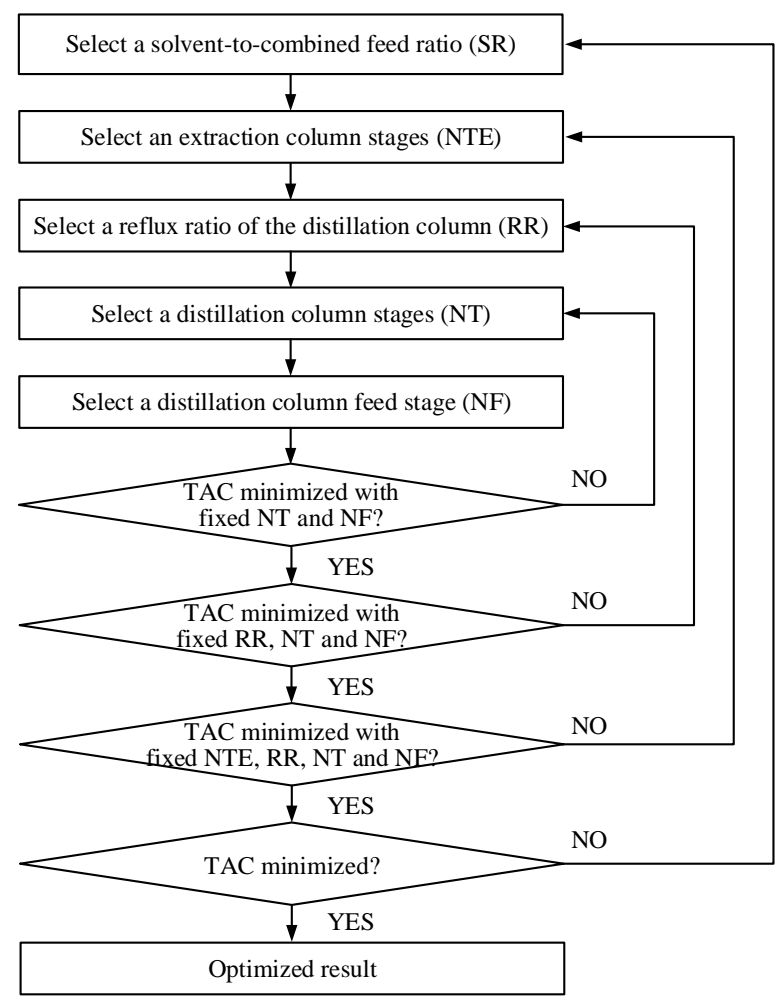

(b)

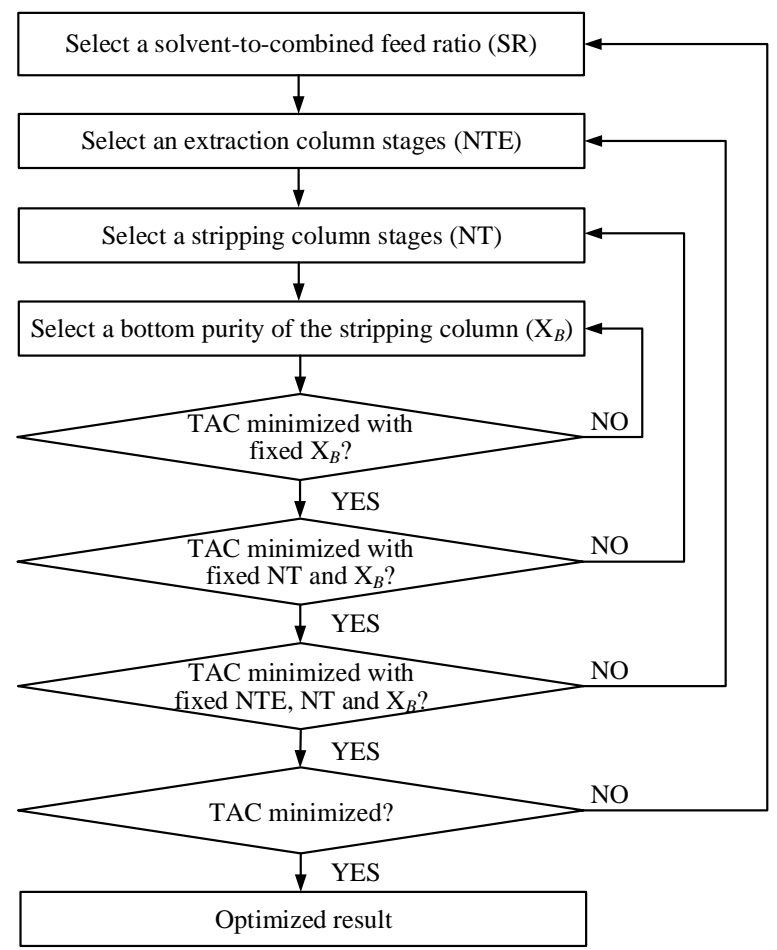


Figure S5. Optimization results for Scheme I of important design variables.

(a)

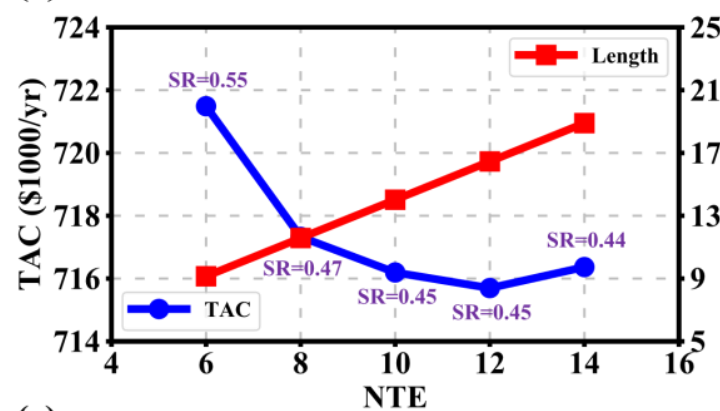

(c)

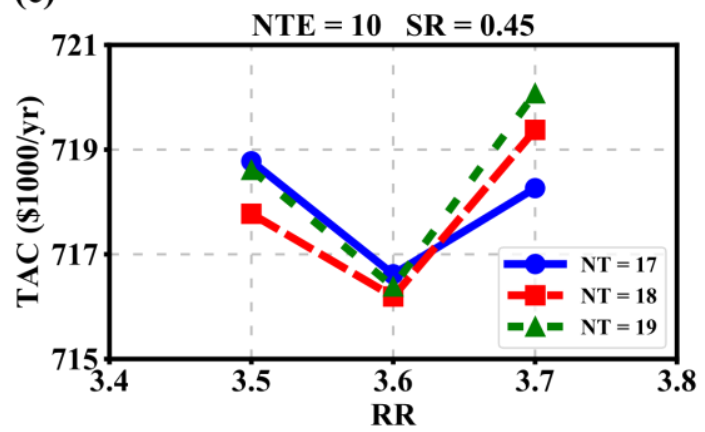

(b)

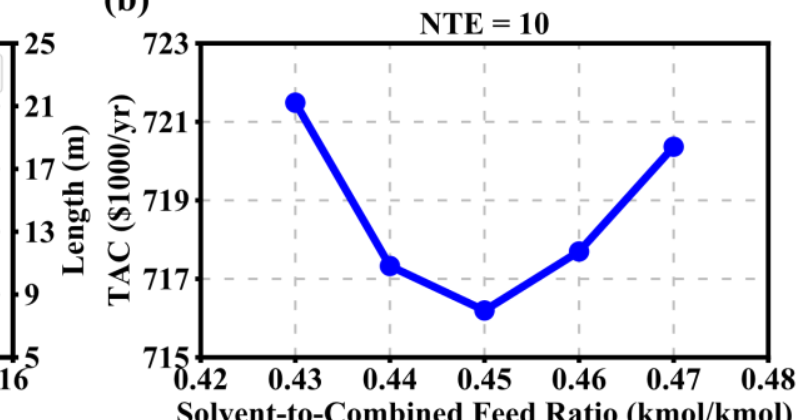

(d)

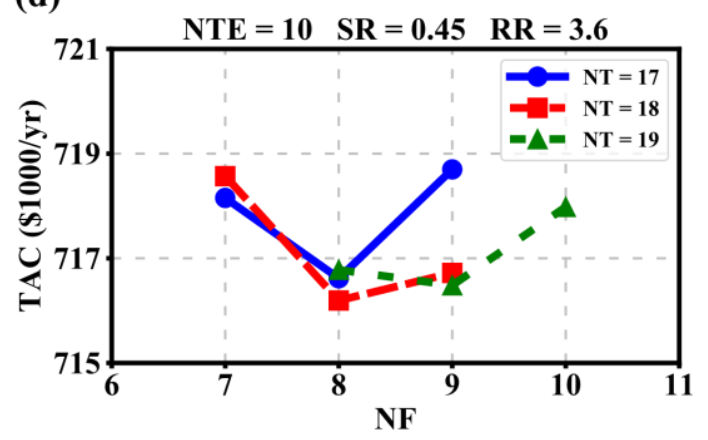


Figure S6. Optimization results for Scheme II of important design variables.

(a)

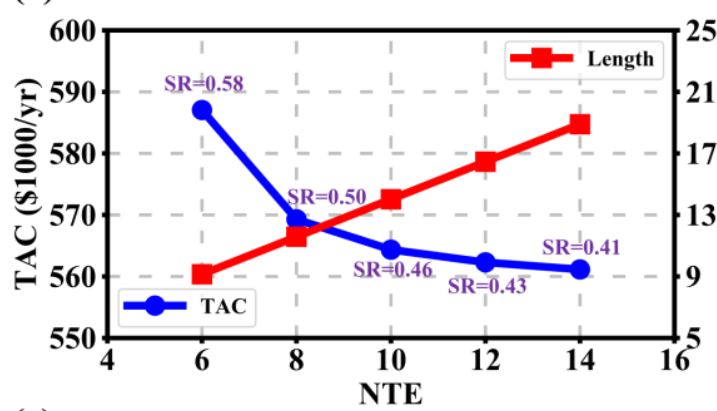

(c)

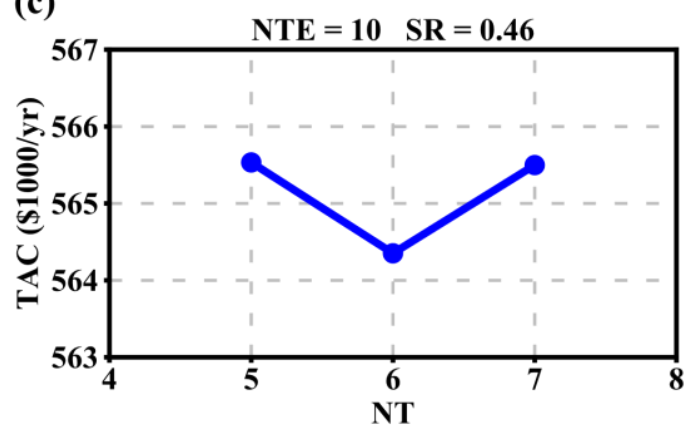

(b)

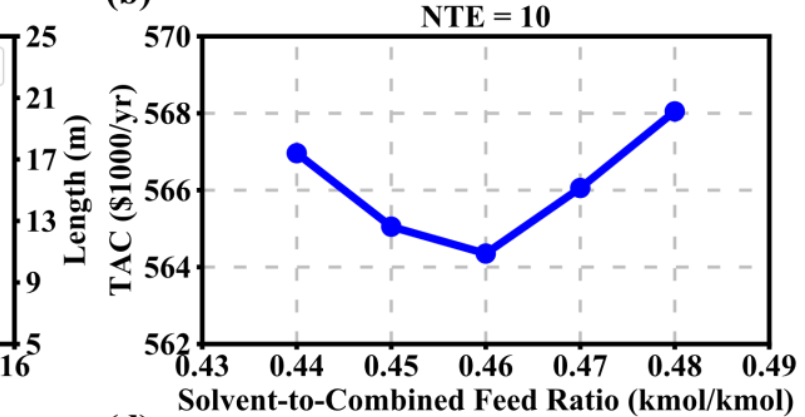

(d)

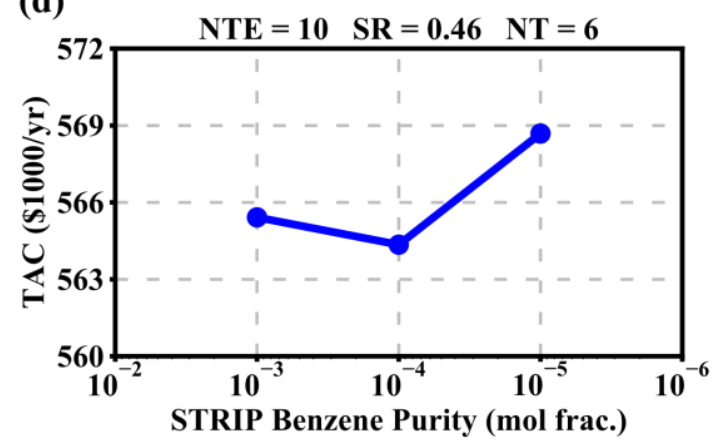


Figure S7. Density difference of each stage in the extraction column for Scheme II.

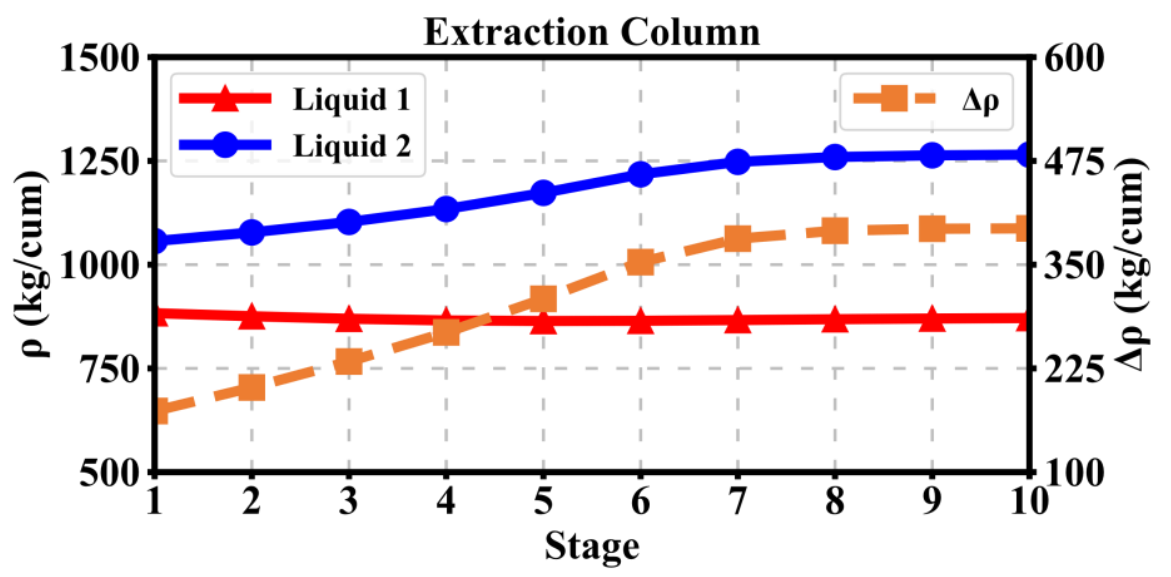


Figure S8. (a) Open-loop sensitivity test with reboiler duty (QR1) on temperature profile in the stripping column (b) Closed-loop sensitivity test on temperature profile in the stripping column.

(a)

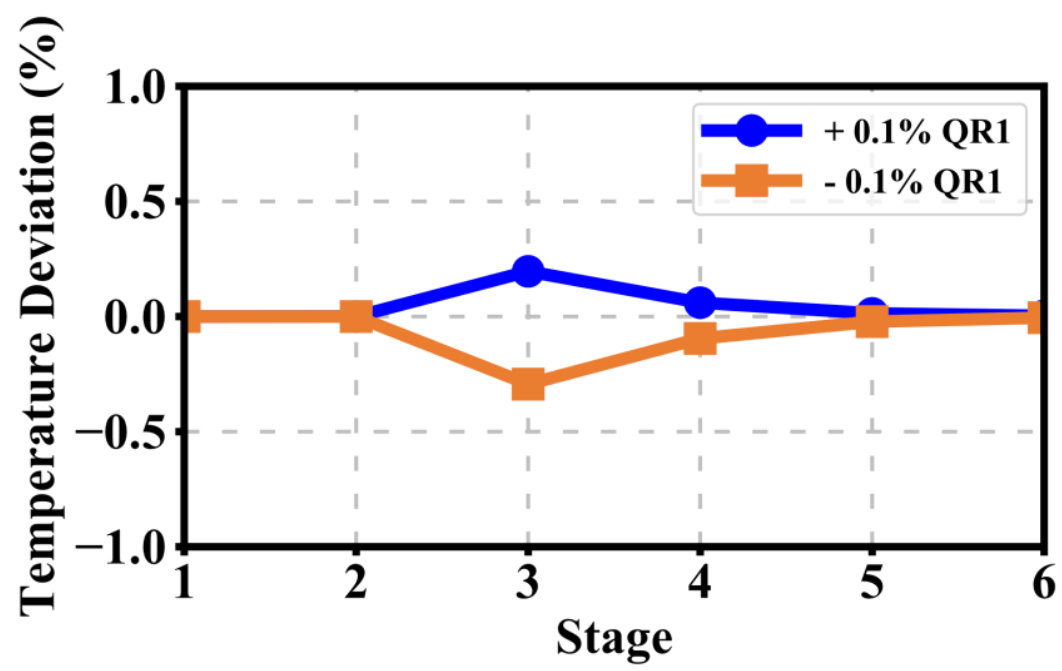

(b)

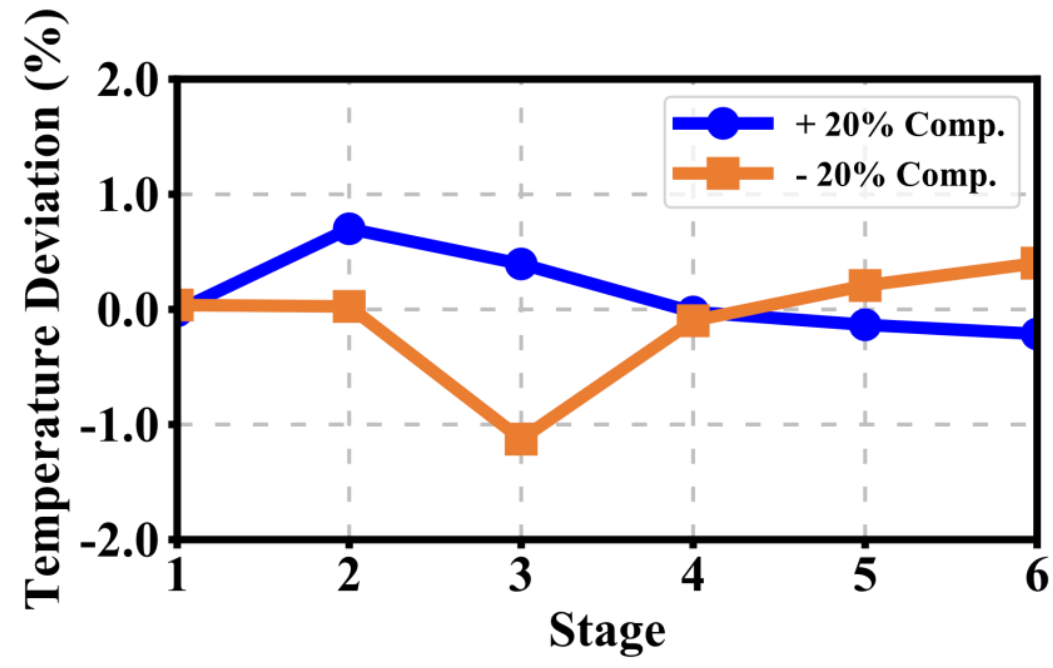

